Anne Ellerup Nielsen

\title{
Argumentative Strategies in French Company Brochures
}

The aim of the thesis is to show how certain strategies of persuasion are expressed and exploited in French company brochures. The theoretical framework of the thesis is the argumentation theory, in which both the new rhetorical and the linguistic approaches to argumentation constitute the key reference. The choice of these two most different approaches to argumentation has to do with the empirical field of the thesis. The company brochure belongs to the genre of advertising and promotion and it can be characterised as a text genre in which the quantity of text and the level of information is relatively important compared to the genre of advertissements for instance. One thing that the company borchure has in common with advertissements in the mass media is the communicative purpose. All genres of advertising and promotion are linked to the idea of promoting a product, and/or a company in order to raise profits. However, the rhetorical means to achieve this goal is quite different in the two subgenres. Advertissements feature many connotations in the form of rhetorical figures (figurative words, metaphors, alliterations etc.). In the company brochure this kind of rhetorical strategy is not very common. The vocabulary is primarily denotative, rational and objective rather than connotative, emotional and expressive which tends to conceal the persuasive purpose which is of course behind all advertising and promoting genres. However, micro linguistic analyses of the deep structure level tend to prove that beyond the rational linguistic surface structure many persuasive markers appear. More specifically the thesis is an attempt to show how these markers cooperate in the discourse in order to create a positive image of the company in the reader's mind. Persuasive strategies are examined in terms of argumentative studies from the smallest linguistic unit represented by the word to micro linguistic sequences of up to two to four propositions.

The thesis is divided into two parts. Part one discusses the theoretical and methodological framework established within rhetoric and argumentation theory. Part two is reserved for empirical studies of small text excerpts taken from company brochures of French industrial companies.

In the introductory chapters (chapters 1-2) of the thesis the empirical field is outlined and inserted into a larger contextual frame of marketing and advertising. Vijay Bathia's model of genre analysis is suggested to account for the company brochure as a particular subgenre of advertising. The company brochure is characterized by a particular thematic structure and composition of 
which the macro-structure is analyzed within the French text linguist JeanMichel Adam's prototypical sequence theory. Different types of sequences (text types), such as the argumentative, the descriptive and the explicative types are described and the brochure is basically categorized, not as an argumentative genre in the sense of a genre which is activating an argumentative programme, but as a mixed genre in which both decriptive and argumentative configurations are found.

Chapter 3 is an outline of three theoretical approaches to argumentation, namely the natural logic approach, the classical rhetorical approach and finally the French linguistic approach according to which argumentation is embedded in language itself. The first of these three approaches is represented by the English scholar Stephen Toulmin who has reorganized the classical formal scheme of argumentation on which both researchers from the linguistic and the new rhetorical tradition base their models of analysis. The Toulmian model is a redefinition of the formal logic components of the classical syllogism: major premise, minor premise and conclusion, in exchange for an argumentative model which is capable of capturing the finer tunes of natural language. His model implies two basic components: an argument (datum) and a conclusion (claim). The datum and the claim are explicit components between which a third and often implicit component functions as a justification (warrant) of the link established between datum and claim.

The second approach to argumentation theory is the new rhetorical tradition pioneered by Chaïm Perelman from the Belgian school of argumentation in Brussels. The new rhetorical tradition is a revival of Aristotelian rhetorics, and this is the reason why the term of argumentation is to be understood in the pragmatic sense as a range of rhetorical forms of which the speaker can make use in an attempt to persuade his audience. An example of this are quantitative arguments, which are referred to as quasi-logical argumentation, because they are parasitic on the formal logical structure. This kind of argumentation is often used when the speaker wants to convince his audience by rational means. The new rhetorical tradition also deals with the problems of causality. Therefore, an attempt to describe the functional differences between causal and evaluative argumentation is made to show how the former type of argumentation does nothing but to claim that there is a particular link between two facts, whereas the latter is an example of how this link is used by the speaker in order to evoke a value judgement.

The third tradition accounted for in the thesis is based on the theory of argumentation within language (AWL) developed by Oswald Ducrot and his colleagues in Paris. According to this theory argumentation is used in another sense than the one we recognize from the rhetorical approach. Argumentation is to be understood as the meaning articulated by words and utterances inde- 
pendently of their referential properties. The theory maintains that language itself articulates meaning by means of argumentative features. The classification of the AWL as a theory of argumentation is justified by the definition of argumentation as an inherent structure in language which implies the two key components of the traditional approach to argumentation: argument and conclusion. An utterance (U1) is asserted and functions as a conclusion expressed in another following utterance (U2): It is raining. I'll go out later!. Ducrot uses terms such as the argumentative point of view and the argumentative orientation to indicate what particular meaning and direction of meaning is implied by a word or an utterance. If we take the weather again and say e.g. It's hot staying in the sun, we constrain ourselves to conclusions which eliminate a positive attitude towards the warm temperature. We can only go on by adding utterances as: We'd better stay in the shadow/Staying in the sun will be bad for your health etc. The step from the first utterance towards the second is based on a particular rule which makes it possible to establish a link between the two utterances. To refer to this rule Ducrot uses the classical Aristotelian term topos. Traditionally topos is to be identified as 'common places' referring to the common rules and conventions on the basis of which we reason within a particular speach community. In this sense topos is connected to our general knowledge of and assumption about how things are combined in the world. If we hear the sentence: This sweater must be washed. It is filthy we are not surprised by this combination, because according to common knowledge it is a general practice, at least in our part of the world, to wash dirty clothes. So, topos is an unwritten warrant that justifies this kind of association between actions and events. The latest current within the Ducrotian approach to argumentation has turned into a topos theory which is claimed to account for the lexical meaning of words. Just as the speaker refers to specific topoi when making an utterance he does the same thing when he uses a particular word, because words with a lexical content are associated with one or more topoi which are constituent of their meaning.

In chapter 4 a model based on the rhetorical and the linguistic approaches to argumentation is proposed in order to analyze the argumentative value of a range of textual sequences. The model is meant to be a methodological instrument for the examination of the argumentative value at the lexical as well as at the utterance level. At the lexical level the orientation of the argument is analyzed to determine whether the argumentation articulated by the use of a word is reinforced or counterbalanced. At the utterance level a closer look is taken first at the topoi articulated by the words and second at the interaction between causal or explicative relations and their linguistic material. As for the analysis of the rhetorical level, understood here as the persuasive impact of the linguistic material observed at the two previous levels, it implies investigations 
of the formal structure of the arguments (are the arguments empirical or quasilogical?), the causal structure of the arguments (does the antecedent fulfil the function of justifiation or cause?) the relationship between personal properties and acts (which types of acts are associated with which types of properties?). Finally, a model of refutation is established to account for the consistency of the arguments.

Chapter 5 rounds off the first part of the thesis and illustrates the use of the model by an exemplary analysis of a single text sequence.

Chapter 6 introduces part two with the empirical analysis and provides a description of the selection and composition of the corpus. A brief account of the macro-structure of the company brochure serves as an illustration of the principle of embedding one sequence into another sequence or text part.

In chapter 7 the selected sequences are subjected to a linguistic analysis of the argumentation articulated at the lexical and the utterance levels. The genre analysis is used as a framework in the selection of prototypical words to be analyzed. It is demonstrated that words with different referential features are nontheless likely to articulate the same meaning from an argumentative point of view, but also that words with identical or similar referential features may differ in respect of argumentative meaning. At the utterance level the analysis tends to point out that a great number of utterances are what might be called doxal, that is utterances in which the semantic connection between the words used and the topoi activated are particularly narrow. Non-doxal utterances are utterances that have a relatively loose topical structure. Furthermore, the analysis of the utterance level includes an examination of the connection between certain types of semantic relations and the use of particular markers such as grâce à, permettre, assurer etc. As these words seem to articulate the concept of possibility they add a value of appreciation to the arguments evoked by the speaker. Thus, the linguistic analysis of the argumentation indicates that the appreciation which is entailed in the genre of promotion seems to be linguistically marked at the micro structural level.

Chapter 8 closes the analysis section of the thesis with an analysis of the argumentation at the rhetorical level. The formal structure of the arguments, the pragmatic function of the causal argumentation, the relation beween personal properties and acts and the refutation possibilities are examined more closely and related to the purely linguistic analysis of chapter 7 . What appears from the rhetorical analysis is that about a third of the sequences reveal a quasilogical structure of argumentation, whereas the rest may be categorized as empirical arguments. Causal sequences that are not quasi-logical all tend to be exploited for pragmatic purposes in so far as the consequent (q) due to certain linguistic and contextual features, is supplied with an implicit value judgement of appreciation. Furthermore, the rhetorical analysis seems to demonstrate that 
the company brochure is a kind of incarnation of the classical category of assessment of a person's properties in terms of his acts and vice versa. In fact, the company's competence, working methods and offers in the market place are presented as a perfect guideline to its position, just as the position of the company is often used as an argument of authority proving that it is worth selecting it for a supplier, a partner, a sponsor etc. Finally, it is concluded that a very common strategy of persuasion manifests itself in the speaker's blocking of the counterpart's possibilities of refutation at the inferential level in cases where $q$ can be supplied with a value judgement of appreciation. As this value judgement is, hovewer, only inferred, the speaker can deny it at any time: Speaker: $p$-> $q$, ( $q$ is impressive): Interlocutor: why are you saying that $q$ is impressive?. Speaker: Who said that $q$ is impressive? I did'nt!

Chapter 9-10 are reserved for the conclusion and final comments on the results of the analysis. Without having representative value, the analysis presents the company brochure as a text genre which, in spite of several informative and rational linguistic and textual features, contains argumentative traces of the act of persuasion under which any genre of advertising and promotion is ultimately subsumed.

\section{References}

Adam, Jean-Michel (1992): Les textes: types et prototypes. Paris: Nathan.

Anscombre, Jean-Claude (1995): "Topique or not topique: formes topiques intrinsèques et formes topiques extrinsèques”. In: Journal of Pragmatics, vol. 24 .

Ducrot, Oswald/Anscombre, Claude (1983a): L'Argumentation dans la langue. Bruxelles: Pierre Mardaga.

Ducrot, Oswald (1988): “Topoï et formes topiques”. In: Bulletin d'études de linguistiques française 22. Tokyio.

Ducrot, Oswald/Bruxelles, Sylvie/Raccah, Pierre-Yves (1993): "Argumentation et champs topiques lexicaux”. In: Cahiers de praxématique 21.

Lundquist, Lita (1990): "Conditions de production et programmation argumentative". In: Verbum, Sémantique et société, 13/4 .

Perelman, Chaïm/Olbrechts-Tyteca, Lucie (1988): Traité de l'argumentation - la nouvelle rhétorique (5. ed.). Editions de l'Université de Bruxelles [ $\left.1^{\mathrm{e}} \mathrm{ed} .1958\right]$.

Plantin, Christian (1990): Essais sur l'argumentation - Introduction linguistique à l'étude de la parole argumentative. Paris: Editions Kimé.

Roubrieux, Jean-Jacque (1993): Eléments de rhétorique et d'argumentation. Paris: Dunod.

Toulmin, Stephen (1969): The uses of argument. Cambridge University Press [1st edn. 1958]. 
